\title{
Suberin of Potato (Solanum tuberosum Var. Nikola): Comparison of the Effect of Cutinase CcCut1 with Chemical Depolymerization
}

\author{
RiIkKa Järvinen, ${ }^{*},{ }^{\dagger}$ Armando J.D. Silvestre, ${ }^{\S}$ Ulla Holopainen, ${ }^{\star}$ \\ Mika Kaimainen, ${ }^{\dagger}$ Antti Nyyssölä,,${ }^{\star}$ Ana M. Gil,${ }^{\S}$ Carlos Pascoal Neto, ${ }^{\S}$ \\ Pekka Lehtinen, Johanna Buchert, ${ }^{\ddagger}$ and Heikki Kallio ${ }^{\dagger}$ \\ 'Department of Biochemistry and Food Chemistry, University of Turku, FI-20014 Turku, Finland, \\ ${ }^{\S}$ CICECO and Department of Chemistry, University of Aveiro, PT-3810-193 Aveiro, Portugal, and \\ *VTT Technical Research Centre of Finland, FI-02044 VTT, Finland
}

\begin{abstract}
Chemical and enzymatic depolymerizations of suberin isolated from potato peel (Solanum tuberosum var. Nikola) were performed under various conditions. Enzymatic hydrolysis with cutinase CcCut1 and chemical methanolysis with NaOMe of suberin yielded monomeric fragments, which were identified as TMS derivatives with GC-MS and GC-FID. The solid, hydrolysis-resistant residues were analyzed with solid state ${ }^{13} \mathrm{C}$ CPMAS NMR, FT-IR, and microscopic methods. Methanolysis released more $\mathrm{CHCl}_{3}$-soluble material than the cutinase treatment when determined gravimetrically. Interestingly, cutinase-catalyzed hydrolysis produced higher proportions of aliphatic monomers than hydrolysis with the NaOMe procedure when analyzed by GC in the form of TMS derivatives. Monomers released by the two methods were mainly $\alpha, \omega$-dioic acids and $\omega$-hydroxy acids, but the ratios of the detected monomers were different, at 40.0 and $32.7 \%$ for methanolysis and 64.6 and $8.2 \%$ for cutinase, respectively. Thus, cutinase CcCut1 showed higher activity toward ester bonds of $\alpha, \omega$-dioic acids than toward the bonds of $\omega$-hydroxy acids. The most abundant monomeric compounds were octadec-9-ene-1,18-dioic acid and 18-hydroxyoctadec-9-enoic acid, which accounted for ca. 37 and $28 \%$ of all monomers, respectively. The results of the analyses of the chemical and enzymatic hydrolysis products were supported by the spectroscopic analyses with FT-IR and CPMAS ${ }^{13} \mathrm{C}$ NMR together with the analysis of the microstructures of the hydrolysis residues by light and confocal microscopy.
\end{abstract}

KEYWORDS: Cutinase; FT-IR; GC-MS; potato; Solanum tuberosum; solid state CPMAS ${ }^{13} \mathrm{C}$ NMR; suberin

\section{INTRODUCTION}

The periderm of potato (Solanum tuberosum L.) tuber forms an effective barrier against desiccation and infection. These functions are achieved mainly by an aliphatic-aromatic cross-linked natural polymer, suberin, which is present in the cell walls of the periderm. Suberized cell walls contain two types of polymeric domains, polyaliphatic and polyphenolic, which are distinct, but covalently linked to each other and to cell wall carbohydrates. Glycerol has been shown to be a linker between these domains, in addition to its role as a linker between monomers in the aliphatic domain. Therefore, glycerol most probably enables the threedimensional network of the suberin structure. As suberin is attached to the cell wall, it is virtually impossible to isolate it in pure and native state, which further complicates structural studies $(1-5)$.

Most of the knowledge on the structure of the aliphatic domain of suberin is based on the analysis of its depolymerization

*Corresponding author (telephone +358 2333 6874; fax +358 2333 6860; e-mail riikka.jarvinen@utu.fi). products obtained predominantly by ester cleavage (e.g., by alkaline hydrolysis or methanolysis). The quantitative composition of monomeric mixtures obtained depends on the method, but consists mostly of long-chain (16-24 carbon atoms) aliphatic dicarboxylic acids, $\omega$-hydroxy fatty acids, very long chain (20-30 carbons) fatty acids, fatty alcohols, and glycerol together with a small amount of aromatic compounds such as coumaric and ferulic acids $(1-5)$. The distribution of the individual suberin monomeric components and compound classes varies between different plant species and parts of plants. As an example, in some bark suberins, the main compounds, are midchain oxidized acids (bearing epoxy and hydroxy functionalities), which are usually thought to be minor components of other plant suberins. The main differences between suberin and another plant biopolyester, cutin, are the location in the plant and the higher proportions of compounds over 20 carbons in suberin. Also, smaller proportions of epoxy and dihydroxy acids than of diacids have been found to be characteristic for suberin. These properties make suberin and cutin extremely diverse natural sources of various hydroxy fatty acid monomers. 
The composition of the polyphenolic domain of suberin is not as well-known as that of the polyaliphatic domain. This fraction has been studied mainly with spectroscopic methods, for example, FT-IR or solid state NMR (4,6-10) or degrading methods, such as thioacidolysis (11). These analyses have shown this fraction to contain mostly substituted hydroxycinnamic acids, especially ferulic acid $(2,11-13)$ with relatively smaller amounts of phenylpropanoid-type structures, similar to lignin monomers $(2,11)$. Feruloyltyramine, a hydroxycinnamyl amide, has also been detected (14).

Potato suberin has been studied both in native and in woundinduced form. Approximately $22-25 \%$ of suberin from the isolated potato peel (treated with cellulase and pectinase and solvent extracted) can be depolymerized by ester cleavage reactions $(5,15,16)$. The main suberin monomer groups identified by GC-MS (main monomer in parentheses) are $\alpha, \omega$-dicarboxylic acids 30-50\% (octadec-9-ene-1,18-dioic acid) and $\omega$-hydroxy acids $15-30 \%$ (18-hydroxyoctadec-9-enoic acid). Some aromatic compounds, fatty alkanols, and fatty acids have also been detected. Glycerol could represent up to ca. $20 \%$ of the total monomers released during depolymerization reactions (5), although this has not always been reported in published studies. This is probably due to the various experimental recovery protocols for monomers after depolymerization. Compounds having odd-numbered carbon chains have been identified from suberin monomers, but their amounts are smaller than those of similar even-numbered-chain compounds (16). Hydroxycinnamate-based polymers with some lignin-like components predominate in the polyphenolic domain of natural and wound-induced potato suberin, but differ from each other in composition $(8,9,11,13)$.

In addition to chemical depolymerization reactions, suberin can also be cleaved enzymatically by specific esterases or lipases. Although various cuticular polyesters are abundant constituents of different raw materials, only a limited set of modifying enzymes, other than conventional lipases, are commercially available for the production of such monomers. Cutinases (CUT, EC 3.1.1.74), in particular, can hydrolyze natural cuticular polyesters (cutin, suberin) to lower molecular weight compounds $(17,18)$. All of the biochemically well-characterized cutinases are esterases, containing the classical SerHisAsp triad common for serine proteases and several lipases, and have a neutral or alkaline $\mathrm{pH}$ optimum. Recently, a novel cutinase CcCUT1 of the basidiomycete Coprinus cinereus was produced recombinantly, purified, and characterized. CcCUT1 is able to hydrolyze both apple cutin and birch outer bark suberin (17). Due to their broad substrate specificities cutinases have been proposed for various applications for processing diverse raw materials (18). With this perspective, these enzymes are potential tools in the food industry as they may be applied to improve the exploitation of several plant materials and for recovering valuable polyfunctional monomers from polyesters such as suberins and cutins.

Significant amounts of cutin and suberin are present in different food and nonfood byproducts, that is, bark cork, berry, fruit and vegetable processing residues, and cereal byproduct. As an example, around $10 \%$ of the fresh weight of potatoes is typically removed during industrial peeling. This industrial waste, composed mainly of skin and tuber flesh, could be a valuable resource of suberin polymers and derived monomers and oligomers. The lack of detailed information on the composition of some of these byproduct materials, and the shortage of suitable enzymes as well as a detailed understanding of the action of those that are available, are the limiting factors for their exploitation. The development of new and more efficient methodologies to isolate suberin/cutin monomeric components, thus ensuring their wide availability, would certainly provide new opportunities in the search for new applications, such as starting materials for the production of novel macromolecular materials, as recently reviewed by Gandini et al. (3).

As a part of a project aimed at discovering and exploiting lipidmodifying enzymes and their reaction products in industrial food and nonfood processes, the objective of this research was to investigate the effect of the novel cutinase CcCUT1 on the hydrolysis of potato suberin and to compare it with conventional chemical depolymerization methods. The resulting monomers were analyzed chromatographically, and the residues that were resistant to enzymatic and chemical hydrolysis were investigated through further chemical depolymerization and cellulase treatment for better understanding of the structures of the suberized tissues.

\section{MATERIALS AND METHODS}

Isolation of Peels and Suberized Tissues. Potatoes (S. tuberosum var. Nikola, grown in Karijoki, Finland) harvested in September 2007 and stored at $4{ }^{\circ} \mathrm{C}$ for 2 months were peeled using a knife, and the peel was boiled for $1 \mathrm{~h}$ and scraped manually with a blade to remove attached flesh. The peel was boiled for another $30 \mathrm{~min}$ to remove all of the remaining starch. Isolated potato peel was oven-dried $\left(50-60^{\circ} \mathrm{C}\right)$ and stored in a sealed container.

The suberin-rich membrane fractions were isolated using a method previously described by Kallio et al. (19). Briefly, the procedure was a combination of enzymatic treatments with cellulase $(5 \mathrm{~g} / \mathrm{L}$ Econase CE, AB Enzymes, Darmstadt, Germany) and pectinase ( $1 \mathrm{~g} / \mathrm{L}$ Pectinex Ultra SP-L, Novozymes, Bagsvaerd, Denmark) in acetate buffer, followed by exhaustive Soxhlet extraction with $\mathrm{CHCl}_{3}$ and $\mathrm{MeOH}(10-12 \mathrm{~h}$ each). The procedure was repeated, and the resulting extractive-free suberin-rich membrane, that is, raw suberin (Figure 1), was washed with water and dried.

Chemical Depolymerization. Chemical depolymerization was carried out with methanolysis under three different conditions (Figure 1). Method 1 and 2 reactions were performed in triplicate, and method 3 was performed in duplicate.

Method 1. Dried samples of the raw suberin $(20 \mathrm{mg})$ were treated with $3 \mathrm{~mL}$ of freshly prepared 1.0 M NaOMe in dry $\mathrm{MeOH}$. The methanolysis was carried out overnight in sealed tubes in a shaker (apprroximately $500 \mathrm{rpm}$ ) at room temperature. The reaction mixture was acidified with $2 \mathrm{M} \mathrm{H}_{2} \mathrm{SO}_{4}(2.0 \mathrm{~mL})$ in $\mathrm{MeOH}$ and the supernatant separated by centrifugation $(1315 \mathrm{~g}, 10 \mathrm{~min}) . \mathrm{H}_{2} \mathrm{O}(10 \mathrm{~mL})$ was added, and the suberin monomers were extracted with $\mathrm{CHCl}_{3}(2 \times 10 \mathrm{~mL})$. The monomer fraction (as methyl esters) in $\mathrm{CHCl}_{3}$ was dried with anhydrous $\mathrm{Na}_{2} \mathrm{SO}_{4}$, filtered, and evaporated to dryness. Suberin monomers (monomer 1, Figure 1) were determined gravimetrically and stored in $\mathrm{CHCl}_{3}$ in a freezer for further analysis.

Method 2. A milder methanolysis reaction was carried out in an overnight reaction of dried samples of raw suberin $(20 \mathrm{mg})$ with $50 \mathrm{mM}$ $\mathrm{NaOMe}$ in dry $\mathrm{MeOH}$ in a shaker (approximately $500 \mathrm{rpm}$ ) at room temperature. The supernatant was separated by centrifugation $(1315 \mathrm{~g}$ $10 \mathrm{~min}$ ), filtered through a $0.45 \mu \mathrm{m}$ filter (Whatman 1, Dassel, Germany), evaporated to dryness, and stored in a desiccator for further analysis (monomer 2, Figure 1).

Method 3. To obtain larger amounts of the depolymerizationresistant solid residue for microscopy, FT-IR, and solid state ${ }^{13} \mathrm{C}$ NMR analysis, the residue was isolated by removing suberin by $\mathrm{NaOMe}-$ catalyzed methanolysis in reflux. A dried sample of raw suberin $(500 \mathrm{mg}$ ) was refluxed for $3 \mathrm{~h}$ with $100 \mathrm{~mL}$ of freshly prepared $1.0 \mathrm{M}$ $\mathrm{NaOMe}$ in dry $\mathrm{MeOH}$ with magnetic stirring. The reaction mixture was filtered (Whatman, Maidstone, U.K.) and the residue on the filter washed with $\mathrm{MeOH}$ until the filtrate was clear and neutral. The residue (residue 1, Figure 1) was further washed with water, oven-dried $\left(50-60{ }^{\circ} \mathrm{C}\right)$, and freeze-dried before analysis. Depolymerized monomers (monomer 3, Figure 1) from this reaction were isolated by $\mathrm{CHCl}_{3}$ extraction according to the method of Kallio et al. (19).

Enzymatic Hydrolysis. The CcCUT1 produced and characterized previously at VTT Biotechnology (Espoo, Finland) (17) was used in the 


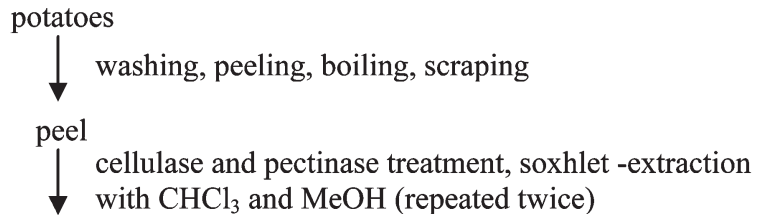

extractive-free suberin-enriched fraction i.e. "raw suberin"

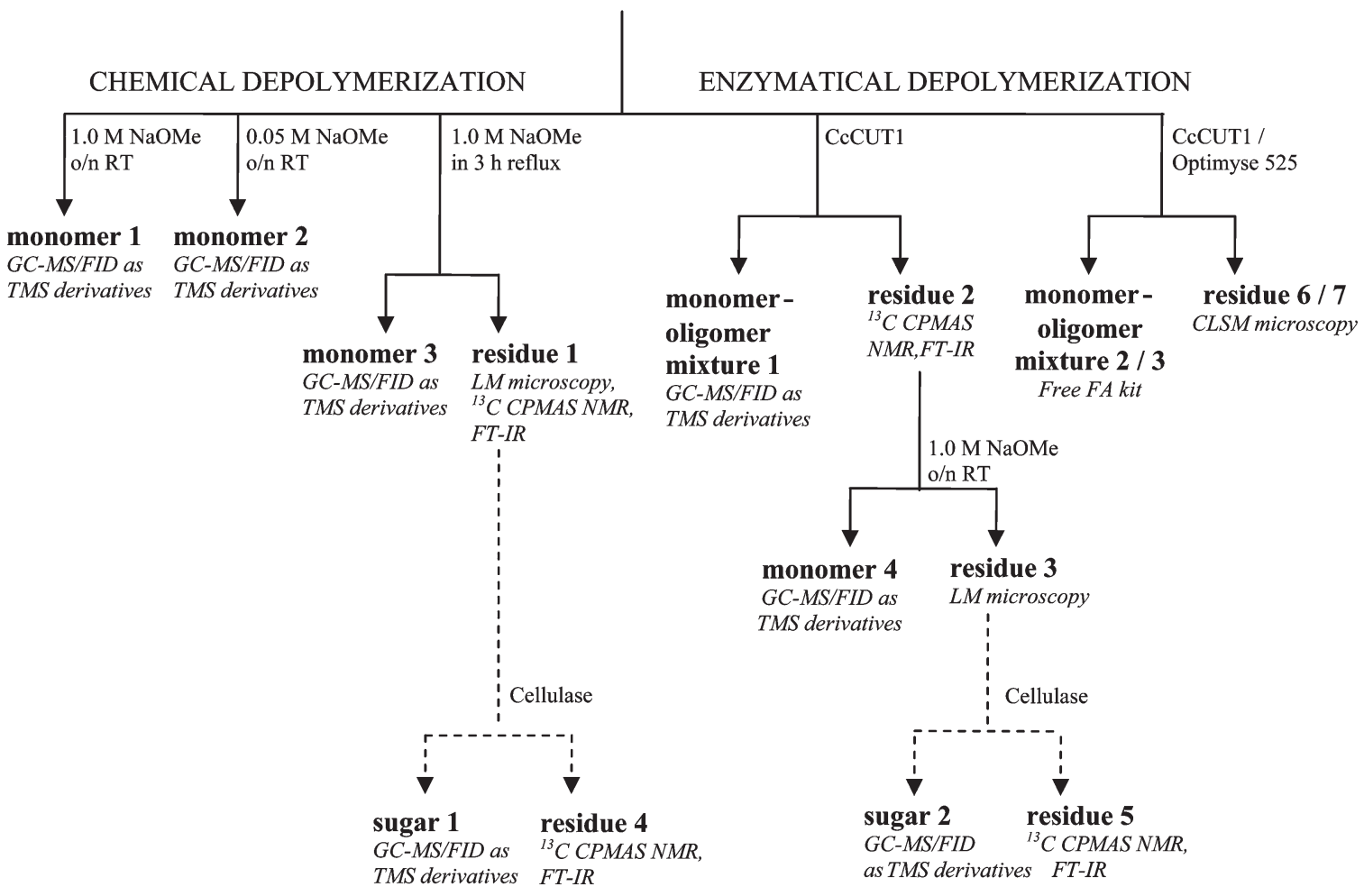

Figure 1. Schematic presentation of the study protocol (bold $=$ isolated fraction, italics $=$ method of analysis).

enzymatic hydrolysis of suberin. Triplicate samples of raw suberin $(50 \mathrm{mg})$ were finely powdered (Mixer Mill, MM301, Retsch, Haan, Germany) and suspended in $2.5 \mathrm{~mL}$ of $0.2 \mathrm{M}$ sodium phosphate buffer, $\mathrm{pH} 8.0$, supplemented with $6.3 \mathrm{mg} / \mathrm{L}$ hydrophobin II (20) and 25000 nkat [as p-nitrophenyl butyrate esterase activity (17)] of CcCUT1. The suspension was incubated at $50{ }^{\circ} \mathrm{C}$ for $48 \mathrm{~h}$ under magnetic stirring. CcCUT1 was omitted from the control samples. After incubation, $\mathrm{MeOH}(0.65 \mathrm{~mL})$ and $\mathrm{H}_{2} \mathrm{SO}_{4}(0.2 \mathrm{~mL})$ were added to the sample, and the product consisting of suberin monomers and oligomers was recovered by three extractions with $2 \mathrm{~mL}$ of $\mathrm{CHCl}_{3}$ each. The chloroform extract was dried with anhydrous $\mathrm{Na}_{2} \mathrm{SO}_{4}$ and centrifuged, and the $\mathrm{CHCl}_{3}$-soluble product (monomer-oligomer mix 1, Figure 1) was evaporated under a gentle stream of nitrogen. The nonhydrolyzable residue (residue 2, Figure 1) was dried. Both products were stored in a desiccator for further analysis.

Products of enzymatic hydrolysis were further analyzed in two separate ways (Figure 1).

Method 4. A sample of monomer-oligomer mixture 1 (Figure 1) was filtered through a $0.45 \mu \mathrm{m}$ filter (Whatman, Dassel, Germany), evaporated under a stream of nitrogen and dried in a desiccator.

Method 5. Hydrolysis-resistant residue (residue 2, Figure 1) was subjected to $1.0 \mathrm{M} \mathrm{NaOMe-catalyzed} \mathrm{depolymerization} \mathrm{overnight,} \mathrm{and}$ monomers were recovered as previously described (monomer 4, Figure 1). The residue (residue 3, Figure 1) was dried for further analysis.

For microscopic examination, the raw suberin $\left(20 \mathrm{mg} \mathrm{mL}^{-1}\right)$ was incubated in the presence of CcCUT1 as described above, with the exception that the suberin particles were not powdered. As a reference, the suberin was also treated with the Optimyze 525 esterase (Buckman Laboratories, Memphis, TN) under the same conditions as above. After the enzymatic hydrolysis, $50 \mu \mathrm{L}$ of $6 \mathrm{M} \mathrm{HCl}$ was added, and the samples were extracted three times with $2 \mathrm{~mL}$ of methyl tert-butyl ether (MTBE) to yield monomer-oligomer mixture 2 from CcCUT 1 and monomer-oligomer mixture 3 from Optimyze 525 treatments (Figure 1). The extracts were divided into two $3 \mathrm{~mL}$ aliquots for monitoring of the free fatty acids released by hydrolysis. The content of monomeric fatty acids was determined from one aliquot and the total amount of both monomeric and oligomeric fatty acids from the other. For the latter analysis, the oligomers were hydrolyzed by adding $935 \mu \mathrm{L}$ of $0.5 \mathrm{M} \mathrm{KOH}$ in $90 \%(\mathrm{v} / \mathrm{v})$ ethanol, and the solution was incubated for $1.5 \mathrm{~h}$ at $70{ }^{\circ} \mathrm{C}$. The solution was neutralized by adding $60 \mu \mathrm{L}$ of $6 \mathrm{M} \mathrm{HCl}$. Monomeric fatty acids of both aliquots were determined using the Free Fatty Acids kit (Roche Diagnostics) with palmitic acid as the fatty acid standard and calculated as moles (17). The content of fatty acids in monomeric and oligomeric forms was compared to the total amount of fatty acids released from the suberin after alkaline hydrolysis. After the MTBE extraction of the hydrolysis products, the solid residue (residues 6 and 7, Figure 1) was washed with water and subjected to microscopic examination.

Analysis of Suberin Monomers. Suberin monomer fractions from the chemical depolymerization (monomers 1-3, Figure 1), cutinase hydrolysis (monomer-oligomer mix 1, Figure 1), and $\mathrm{CHCl}_{3}$-soluble fraction after chemical depolymerization of the cutinase-resistant residue (monomer 4, Figure 1) were further trimethylsilylated before chromatographic analysis using the Tri-Sil reagent (HMDS and TMCS in pyridine) (Pierce Chemicals Co., Rockford, IL), after being dried in a desiccator. Following addition of the reagent, the samples were vigorously shaken at room temperature for $5 \mathrm{~min}$ and incubated at $60{ }^{\circ} \mathrm{C}$ for $15 \mathrm{~min}$. The monomer composition was determined by GC-EI-MS with a Shimadzu GC-MS QP5000 instrument (Shimadzu, Kyoto, Japan) in the following chromatographic conditions: $30 \mathrm{~m} \times 0.25 \mathrm{~mm}$ i.d. $\times 0.25 \mu \mathrm{m} \mathrm{d}_{\mathrm{f}}$, DB-1 MS column (Agilent J\&W, Folsom, CA); split injection (14:1); carrier gas $\mathrm{He}$ (linear velocity $=42 \mathrm{~cm} / \mathrm{s}$ ); injector and detector temperatures $=300{ }^{\circ} \mathrm{C}$. The oven temperature was programmed from $100{ }^{\circ} \mathrm{C}$ at $10{ }^{\circ} \mathrm{C} / \mathrm{min}$ to $220^{\circ} \mathrm{C}$, from $220{ }^{\circ} \mathrm{C}$ at $3{ }^{\circ} \mathrm{C} / \mathrm{min}$ to $290^{\circ} \mathrm{C}$, and kept for $15 \mathrm{~min}$ at $290^{\circ} \mathrm{C}$. Mass range $m / z 45-550$ was acquired. As a comparison of different detection methods FID (Shimadzu GC 17A, Kyoto, Japan) was used in 
Table 1. Gravimetric and Surface Area Results of Potato Peel, Isolated Suberized Membrane, Suberin Monomers, and Depolymerizable-Resistant Residue with Chemical Depolymerization and Cutinase Hydrolysis

\begin{tabular}{|c|c|c|c|}
\hline & & per weight of fresh potato & per area of peel \\
\hline peel & & $\begin{array}{l}1.82 \mathrm{mg} / \mathrm{g} \pm 0.23 \mathrm{mg} \\
1.03 \mathrm{~cm}^{2} / \mathrm{g} \pm 0.10 \mathrm{~cm}^{2}\end{array}$ & $1.76 \mathrm{mg} / \mathrm{cm}^{2} \pm 0.16 \mathrm{mg}$ \\
\hline isolated suberized membrane (raw suberin) & & $1.00 \mathrm{mg} / \mathrm{g} \pm 0.07 \mathrm{mg}$ & $0.96 \mathrm{mg} / \mathrm{cm}^{2} \pm 0.06 \mathrm{mg}$ \\
\hline chemical depolymerization & $\begin{array}{l}\mathrm{CHCl}_{3} \text {-soluble product } \\
\text { residue }\end{array}$ & $\begin{array}{l}0.27 \mathrm{mg} / \mathrm{g} \pm 0.02 \mathrm{mg} \\
0.55 \mathrm{mg} / \mathrm{g} \pm 0.02 \mathrm{mg}\end{array}$ & $\begin{array}{l}0.26 \mathrm{mg} / \mathrm{cm}^{2} \pm 0.02 \mathrm{mg} \\
0.53 \mathrm{mg} / \mathrm{cm}^{2} \pm 0.02 \mathrm{mg}\end{array}$ \\
\hline cutinase hydrolysis & $\begin{array}{l}\mathrm{CHCl}_{3} \text {-soluble product } \\
\text { residue }\end{array}$ & $\begin{array}{l}0.14 \mathrm{mg} / \mathrm{g} \pm 0.02 \mathrm{mg} \\
0.69 \mathrm{mg} / \mathrm{g} \pm 0.01 \mathrm{mg}\end{array}$ & $\begin{array}{l}0.14 \mathrm{mg} / \mathrm{cm}^{2} \pm 0.02 \mathrm{mg} \\
0.66 \mathrm{mg} / \mathrm{cm}^{2} \pm 0.01 \mathrm{mg}\end{array}$ \\
\hline
\end{tabular}

addition to MS detection, under the conditions described above. All monomer proportions were calculated as average peak area percentage of total peak areas from MS and FID chromatograms.

Compounds were identified by comparing the EI-MS spectra of their TMS derivatives (methyl ester TMS ether or TMS ester TMS ether) with those of reference compounds, with published spectra (21-24), and with typical fragmentation patterns with the aid of retention times. This information has previously been summarized by Kallio et al. (19). The positions of the double bonds were not confirmed by chemical methods. Cholesterol as a TMS derivative was used as an internal standard when determining the relative degree of depolymerization of different fractions.

Sugar Analysis. Residues after chemical depolymerization (residue 1, Figure 1) and cutinase hydrolysis (residue 2, Figure 1) were subjected to a second cellulase treatment in an attempt to remove the remaining, evidently originally shielded, cellulosic material, which was observed in the FT-IR and solid state ${ }^{13} \mathrm{C}$ NMR experiments (see Results and Discussion). An aliquot of residue 1 served as a control, without the enzyme in the mixture. Sorbitol was added to each residue as an internal standard, and the sample was incubated overnight at $37^{\circ} \mathrm{C}$ with $5 \mathrm{~mL}$ of $50 \mathrm{mM}$ acetate buffer ( $\mathrm{pH} 4.0$ ) containing $12 \mathrm{~g} / \mathrm{L}$ cellulase (Econase CE, AB Enzymes, Darmstadt, Germany). The reaction mixture was separated by centrifugation $(1315 \mathrm{~g}, 5 \mathrm{~min})$, and the supernatant was fractionated following a method previously described by Tiitinen et al. (25). A sample of the sugar fraction was evaporated to dryness and dried in a desiccator overnight. TMS derivatives of sugars were prepared by adding Tri-Sil reagent (Pierce, Rockford, IL) into each fraction, followed by vigorous shaking for $5 \mathrm{~min}$ and incubation at $60{ }^{\circ} \mathrm{C}$ for $30 \mathrm{~min}$. Sugars were analyzed with GC-FID and identified by GC-MS and reference compounds. In addition to sugar fractions 1 and 2 (Figure 1), cellulase-resistant residues (residues 4 and 5, Figure 1) were also obtained and further analyzed after drying.

FT-IR and Solid State ${ }^{13}$ C NMR Analyses. Samples of nondepolymerizable residue from both chemical (residue 1, Figure 1) and enzymatic hydrolysis (residue 2, Figure 1) and the residues remaining after the second cellulase treatment (residues 4 and 5 Figure 1) were subjected to Fourier transform infrared spectroscopy (FT-IR) and solid state ${ }^{13} \mathrm{C}$ crosspolarization magic angle spinning (CPMAS) NMR analyses. The FT-IR spectra were recorded with a Spectrum BX FT-IR (Perkin-Elmer, Waltham, MA) equipped with Spectrum v5.3.1 software. FT-IR spectra were measured with a resolution of $4 \mathrm{~cm}^{-1}$ and 16 scans per sample. ${ }^{13} \mathrm{C}$ CPMAS spectra were recorded on a Bruker Avance-400 (DRX) NMR spectrometer operating at $400 \mathrm{MHz}$ for proton and at $100 \mathrm{MHz}$ for carbon, using a $7 \mathrm{~mm}$ CPMAS Bruker double-bearing probe. Rotors were spun at rates of $5 \mathrm{kHz}$, and the ${ }^{13} \mathrm{C}$ CPMAS spectra were recorded using a proton $90^{\circ}$ pulse length of $4.0-4.5 \mu \mathrm{s}, 1 \mathrm{~ms}$ contact time, and a recycle time of $5 \mathrm{~s}$. The number of scans depended on the amount of sample available and is stated in the caption of Figure $\mathbf{4}$ separately for each sample.

Microscopic Analyses. Enzymatic modifications of raw suberin with CcCUT 1 and Optimyze 525 were visualized using confocal laser scanning microscopy (CLSM, residues 6 and 7, Figure 1) equipment consisting of a Bio-Rad Radiance Plus confocal scanning system (Bio-Rad, Hemel Hempstead, Hertfordshire, U.K.) attached to a Nikon Eclipse E600 microscope (Nikon Corp., Tokyo, Japan). For imaging, samples were stained in $0.01 \%$ (w/v) Nile Blue (Gurr Products, Romford, Essex, U.K.) for $2 \mathrm{~min}$ and rinsed with water. Surfaces and newly cut cross sections of the material were examined using a $488 \mathrm{~nm}$ argon laser line for excitation and band-pass filters at 500-560 and 575-625 $\mathrm{nm}$ for green and red fluorescence, respectively. 3D green- and red-filtered emission images of the optical sections were obtained using either a 10 $\times$ objective (Nikon Plan Apo, numerical aperture 0.45 ) to the depth of $40 \mu \mathrm{m}$ with a $4.0 \mu \mathrm{m} \mathrm{z}$ step, $1.0 \mu \mathrm{m}$ pixel size, and resolution of $512 \times 512$ or a $20 \times$ objective (Nikon Plan Apo, numerical aperture 0.75) to the depth of $24 \mu \mathrm{m}$ with $2.0 \mu \mathrm{m} \mathrm{z}$ step, $0.5 \mu \mathrm{m}$ pixel size, and resolution of $512 \times 512$. The final CLSM micrographs were reconstructed by the superimposition of a green-filtered emission image and a red-filtered emission image, in which suberincontaining cell walls appeared yellow.

Residue 1 from chemical depolymerization and residue 3 from cutinase hydrolysis followed by chemical depolymerization were analyzed by light microscopy (LM, Figure 1) due to their fine particle size, which made them unsuitable for confocal microscopy. The samples for LM analysis were prepared as previously described by Olkku et al. (26). Briefly, the samples were fixed in $1 \%$ glutaraldehyde in $0.1 \mathrm{M}$ phosphate buffer ( $\mathrm{pH} 7)$, dehydrated with ethanol, embedded in Historesin, and sectioned $(2 \mu \mathrm{m})$ with a rotary microtome. For microscopic examination the sections were stained with $0.5 \%$ Oil Red O (BDH Chemicals, Poole, Dorset, U.K.) in $70 \%$ ethanol for $1 \mathrm{~min}$. Suberin-containing structures appear as yelloworange stained structures in the micrographs.

An overview of the study protocol and all of the obtained products is shown in Figure 1.

\section{RESULTS AND DISCUSSION}

Isolation of Suberized Membrane Fraction (Raw Suberin), Chemical Depolymerization, and Cutinase Hydrolysis. The surface area of the potato tubers varied according to their size and was between 79 and $140 \mathrm{~cm}^{2}$ per tuber. The average results of gravimetric and surface area measurements of potato peel, raw suberin, chemical depolymerization and cutinase hydrolysis products (monomer 1 and monomer-oligomer mix 1, Figure 1), and the residues from both reactions (residues 1 and 2, Figure 1) are shown in Table 1.

The mass of washed potato peel was on average $0.18 \%$ of the tuber fresh weight. The raw suberin accounted for 55\% (SD 4\%) of peel and ca. $0.1 \%$ of potato fresh weight. Suberin monomer 1 , released by $1.0 \mathrm{M} \mathrm{NaOMe-catalyzed} \mathrm{methanolysis,} \mathrm{corresponded}$ to $27 \%$ (SD $2 \%$ ) of the total suberin, leaving $56 \%$ (SD $2 \%$ ) of the nondepolymerizable residue, the remaining 18\% (SD 4\%) being water-soluble material. The gravimetric results from the overnight reaction were comparable to results from the $3 \mathrm{~h}$ reflux reaction (monomer 3, 27\%, SD 3\%; residue $1,57 \%$, SD 1\%; water-soluble, $16 \%$, SD 1\%), which resulted in complete depolymerization of the ester-bound suberin according to FT-IR and solid state ${ }^{13} \mathrm{C}$ NMR (see below). These results are consistent with previously published information for potato suberin $(5,15)$.

Enzymatic hydrolysis with cutinase CcCUT 1 yielded 15\% (SD $2 \%$ ) of $\mathrm{CHCl}_{3}$-soluble product (monomer-oligomer mix 1, Figure 1). The residue from cutinase hydrolysis (residue 2), which accounted for $72 \%$ (SD 1\%) of the total, was subjected to chemical depolymerization, yielding an additional $11 \%$ of $\mathrm{CHCl}_{3}$-soluble monomers and a residue (residue 3). These 
combined yields together are comparable with the yield obtained by chemical depolymerization.

Suberin Monomeric Composition. The composition of suberin monomers, released from the raw suberin by methanolysis or by CcCUT 1 hydrolysis, was identified on the basis of GC retention times and EI-mass spectra as TMS ethers of methyl or TMS esters. Only a few reference compounds were available (given in Table 2), and thus the retention behaviors and the mass spectral fragmentation patterns were the main methods of identification $(19,21-24)$. The diagnostic ions and retention times of each derivative are shown in Table 2.

To find out, in general, how effectively raw suberin was depolymerized with the various methods (Figure 1), the yields of the released soluble fractions were determined gravimetrically. The derivatized monomers were further analyzed by GC using cholesterol as an internal standard. The chromatographic results were calculated by comparing the total peak area of all analytes to the peak area of cholesterol (Figure 2). Even though correction factors for the monomer derivatives were not determined due to the lack of reference compounds, relative differences between the five fractions could be defined. The results also revealed that all of the methods left, in addition to the polymeric fraction, soluble remnant compounds that were not detected in $\mathrm{GC}$ analysis. This was in accordance with earlier published results $(4,5)$.

The most effective depolymerization took place with $1.0 \mathrm{M}$ NaOMe-catalyzed methanolysis, yielding almost twice the amount of $\mathrm{CHCl}_{3}$-soluble compounds produced in the cutinase hydrolysis. Interestingly, the results from the GC analysis showed that the enzymatic hydrolysis produced relatively more of the compounds analyzable with GC even though the total degree of depolymerization was clearly lower. Thus, cutinase treatment seems to be a more selective method for releasing aliphatic hydroxy fatty acids and dicarboxylic acids from suberin than the chemical methods, indicating the potential for specific industrial purposes.

Results from the analysis of suberin monomers (Table 3) obtained from the peel of potato variety Nikola by $1.0 \mathrm{M}$ $\mathrm{NaOMe}$-catalyzed methanolysis were similar to results found in the literature for other potato varieties (e.g., Irmgard, Russet Burbank) in which different depolymerization techniques were used $(8,21,22)$. The most abundant compound groups were $\alpha, \omega$ diacids and $\omega$-hydroxy acids, accounting together for $>70 \%$ of monomers, with small proportions of fatty acids, alcohols, and aromatic compounds. The most abundant compounds were octadec-9-ene-1,18-dioic acid and 18-hydroxyoctadec-9-enoic acid, which accounted ca. for 37 and $28 \%$, respectively, of all monomers. These monomers have been reported to be the most abundant compounds in potato suberin $(5,15,16)$. All monomer proportions were calculated as the average peak area percent of total peak areas from MS (Figure 3) and FID chromatograms. Some short-chain (4-9 carbon chain) $\alpha, \omega$-diacids and $\omega$-hydroxy acids, which have also been reported for cork suberin (4), were also detected in the studied samples.

Methanolysis catalyzed by $1.0 \mathrm{M} \mathrm{NaOMe}$ at room temperature overnight yielded a similar relative proportion of monomers as the $3 \mathrm{~h}$ reaction in reflux. With lower $\mathrm{NaOMe}$ concentration the composition of the hydrolysis mixture was substantially different; for example, the amount of $\omega$-hydroxy acids was lower and epoxy acids were absent. Similar results have previously been reported for suberin depolymerization with several different $\mathrm{NaOMe}$ concentrations $(4,27)$. Glycerol has been reported to be an important unit of suberin $(2,3,5)$, but depending on the method used it might not be quantifiable as it may be discarded due to its water solubility. With the milder $\mathrm{NaOMe}$ concentration, the water-chloroform partitioning after methanolysis could be omitted, and the amount of glycerol determined (ca. 20\% of total peak areas in GC-MS and FID chromatograms) was consistent with earlier results from potato suberin hydrolysis (variety not known) (5). With the exception of glycerol, the most abundant compounds were the same when different concentrations of $\mathrm{NaOMe}$ were used for methanolysis (Table 3).

The monomers released by CcCut1 (monomer-oligomer mix 1, Figure 1) were the same as the monomers from chemical depolymerization, but the ratio of $\omega$-hydroxy acids to $\alpha, \omega$-diacids was significantly lower in enzymatic hydrolysis (Table 3). Epoxysubstituted monomers were absent in cutinase hydrolysis products, just as they were in the milder $\mathrm{NaOMe}$ methanolysis. The residue from the enzymatic hydrolysis (residue 2, Figure 1) was also subjected to chemical depolymerization to solubilize the remaining ester-bound suberin monomers, which were shown to exist in the product by FT-IR and solid state ${ }^{13} \mathrm{C}$ NMR (see later in the text). This reaction yielded monomer fraction 4 (Figure 1), which contained more $\omega$-hydroxy acids compared to $\alpha, \omega$-diacids and more unidentified compounds than the other methods (Table 3). About 7\% of hydrocarbons were also detected by GC-MS, but were absent in all other experiments.

The results of the monomer analysis of the cutinase-containing reaction mixtures showed a clear predominance of $\alpha, \omega$-diacids over $\omega$-hydroxy acids when compared with chemical depolymerization with 1.0 M NaOMe (Table 3). Furthermore, the results obtained from the cutinase hydrolysis were more similar to those obtained with milder methanolysis, but relatively more of the cutinase product can be analyzed with GC in the form of TMS derivatives (Figure 2). These results together indicate that cutinase has a higher specificity for the hydrolysis of $\alpha, \omega$-diacids rather than $\omega$-hydroxy acids. This could be because the former are mainly involved in more labile glyceryl-ester bonds, whereas the latter are in the form of less reactive wax-type ester bonds (1-4). In addition, the prevalence of the $\alpha, \omega$-diacids over $\omega$-hydroxy acids could also be the result of the various organizations of the units in the polymer and the various amounts of cross-linkages. Also, the absence of released epoxy acids under milder conditions of chemical depolymerization or by cutinase hydrolysis may be explained by their hindered structure and location in the suberin layers. It is also possible that this may be due to opening of the epoxy rings due to the method of hydrolysis. In the case of cutinase-catalyzed hydrolysis, this produces a small rise in the corresponding dihydroxydioic acids and trihydroxy fatty acids, although this does not totally explain the differences.

Solid State ${ }^{13}$ C NMR and FT-IR Analysis of DepolymerizationResistant Residues. Additional information on the mode of action of the cutinase CcCUT1 compared with chemical depolymerization can be achieved from the solid residues obtained from the reactions. Due to their insoluble nature, the residues from chemical depolymerization (residue 1, Figure 1) and cutinase hydrolysis (residue 2, Figure 1) were analyzed by solid state ${ }^{13} \mathrm{C}$ CPMAS NMR and by FT-IR. Both techniques have previously been used successfully, for example, in cork and potato suberin analysis $(4,6-10)$, one study tackling, in particular, the effects of suberin removal (10). In these studies, comparative spectra from unreacted, that is, raw suberin with depolymerization residue and suberin extracts have been published and differences reviewed.

The ${ }^{13} \mathrm{C}$ CPMAS NMR and FT-IR spectra of these residues (Figures 4 and 5) confirm the results obtained from the other analyses and from previous observations on similar residues $(9,10)$. The spectra of residue 1 (Figure 4A) showed a clear predominant cellulose profile $\left(64 \mathrm{ppm} \mathrm{C}_{6} ; 72-74 \mathrm{ppm} \mathrm{C}_{2}, \mathrm{C}_{3}, \mathrm{C}_{5}\right.$; 82-90 ppm $\mathrm{C}_{4} ; 105 \mathrm{ppm} \mathrm{C}_{1}$ ) overlapping with resonances from lignin-like structures $\left(56 \mathrm{ppm}-\mathrm{OCH}_{3} ; 62 \mathrm{ppm}-\mathrm{CH}_{2} \mathrm{O}-\right.$; 


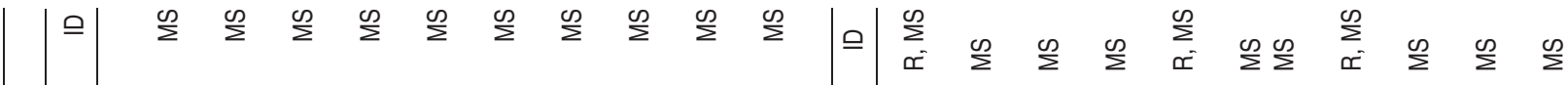

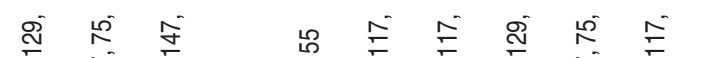

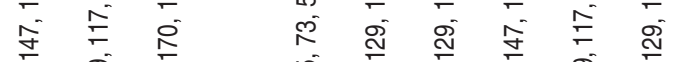

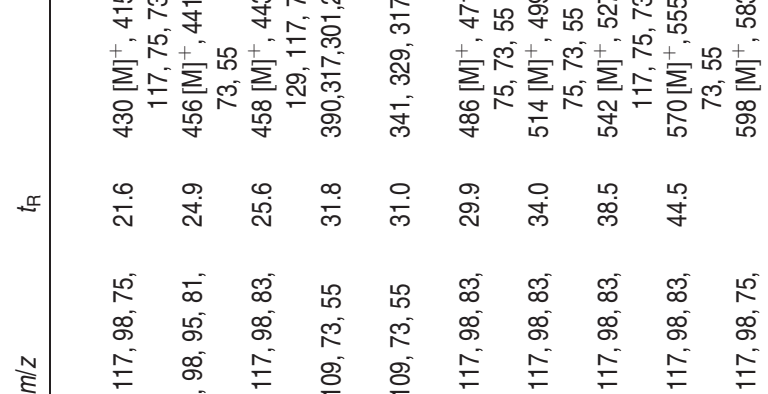

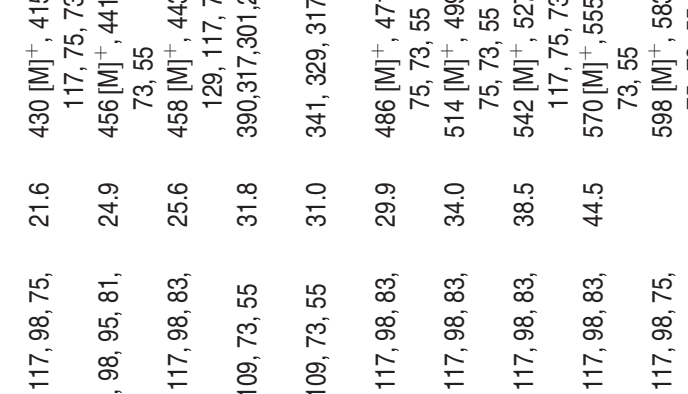

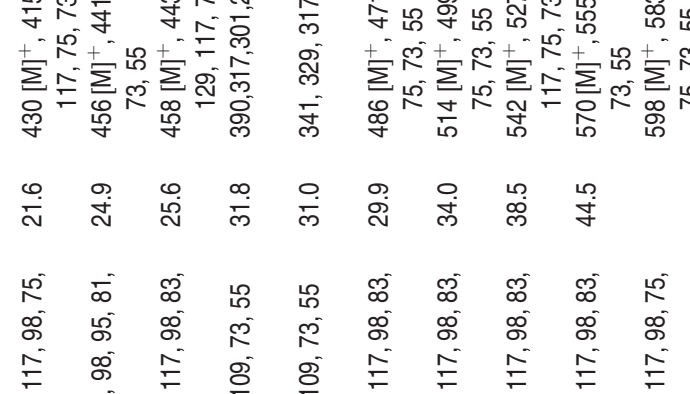

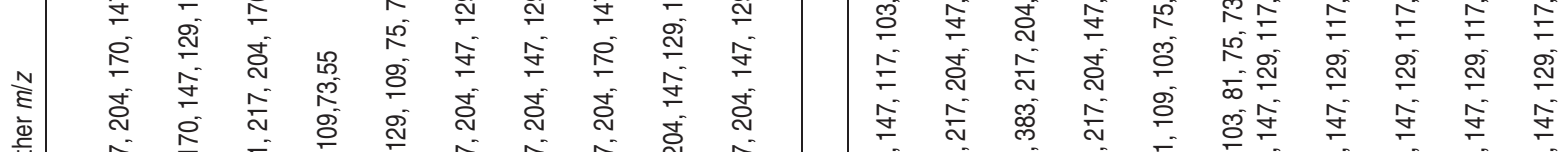

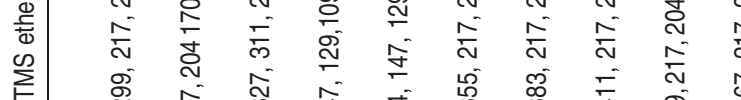

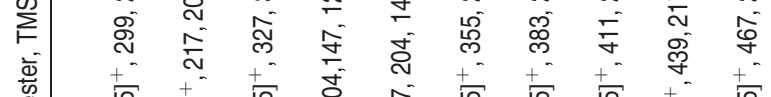

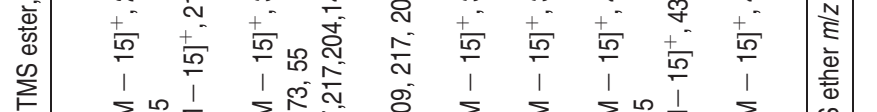

के

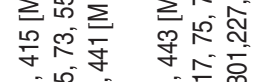
全

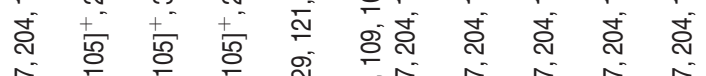

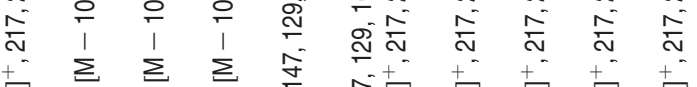

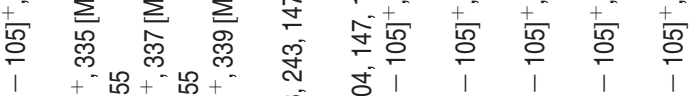

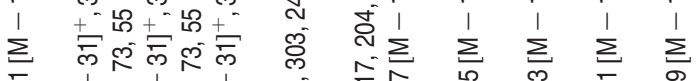

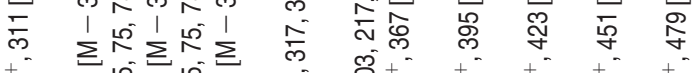

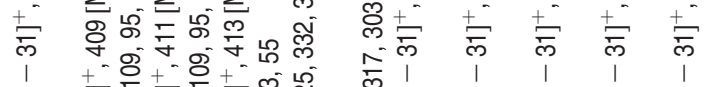

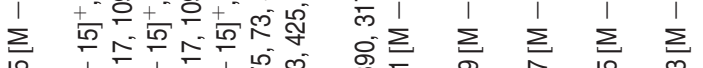

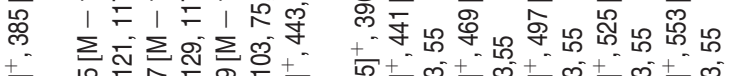

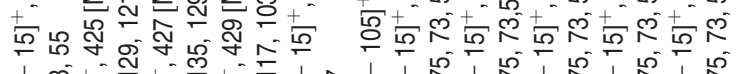

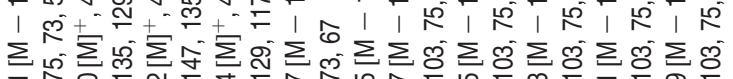

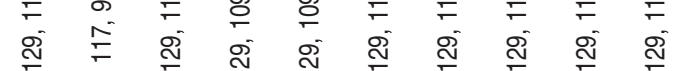

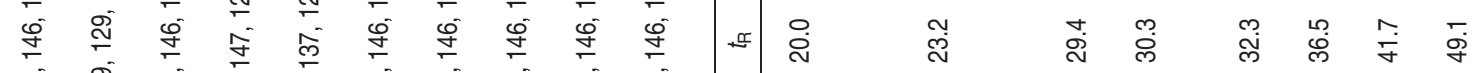

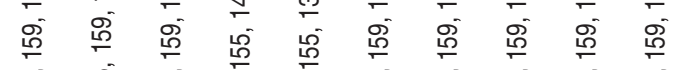

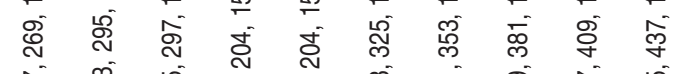

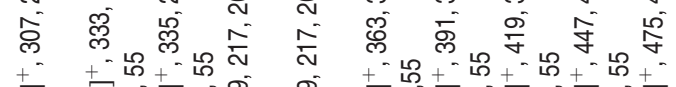

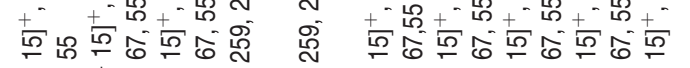

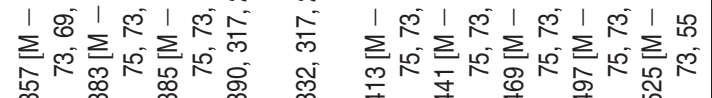

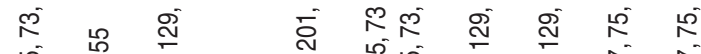

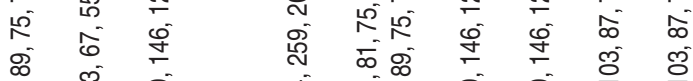

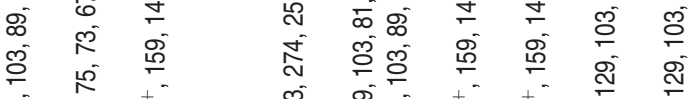

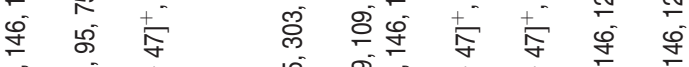

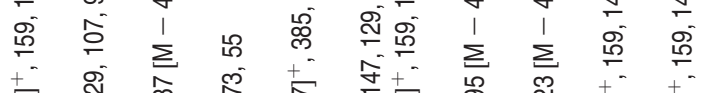

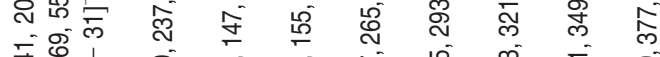

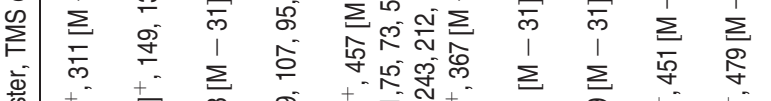

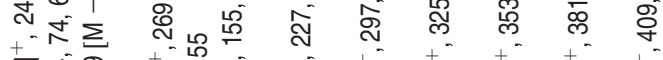

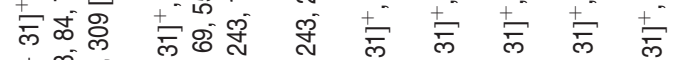

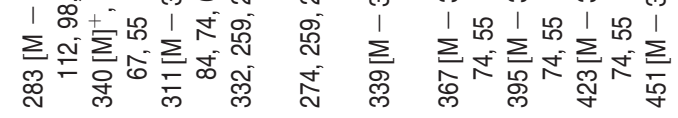

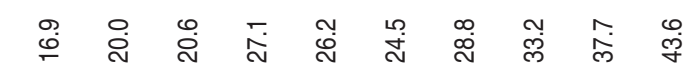
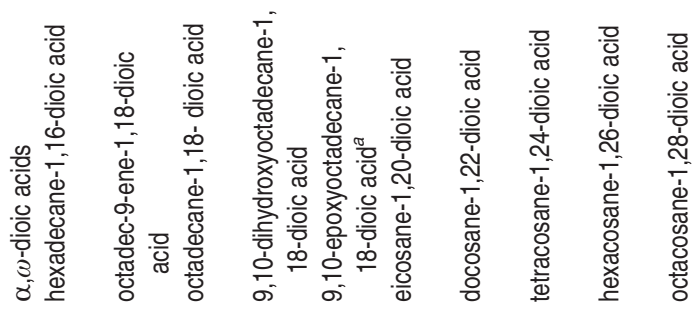

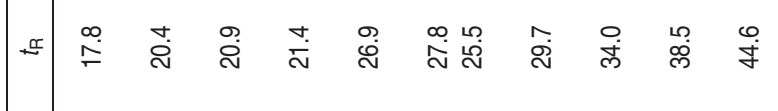
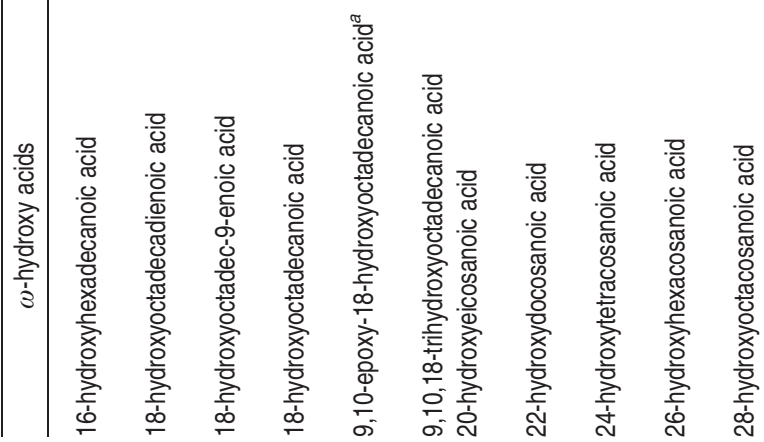


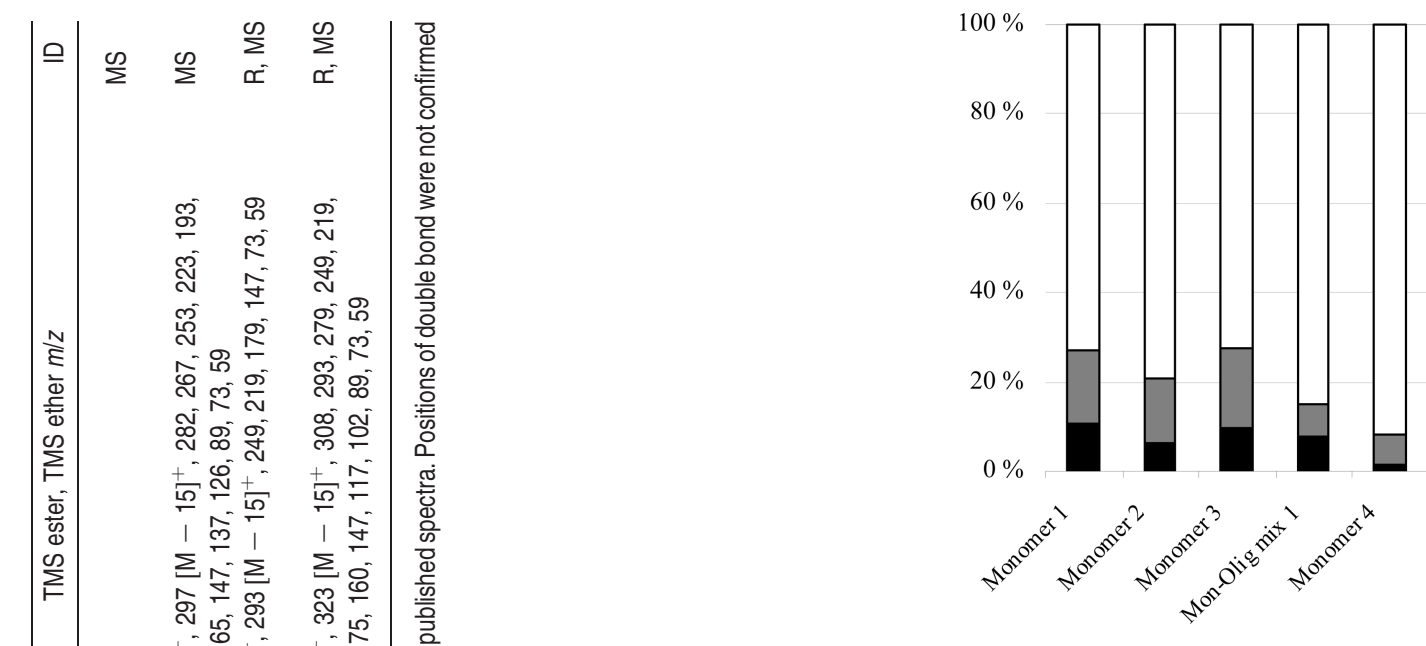

Figure 2. Hydrolysis yield of the chloroform-soluble compounds detected by gravimetric analysis (gray + black) and proportion of the monomeric compounds detected by $\mathrm{GC}$ analysis (black) released from the raw suberin samples (100\%).

83 ppm CHOAr; 90 ppm CHO-, 105-150 ppm arom $-\mathrm{CH}-$ and quaternary C) $(6,7,9,10)$. The signals at $170-180 \mathrm{ppm}$ should arise from carbonyl resonances possibly present in aromatic structures and/or polysaccharides such as pectin or hemicellulose or, eventually, of suberin components. The corresponding FT-IR spectrum (Figure 5A) confirmed the absence of ester-bonded aliphatic structures (no band at $1750 \mathrm{~cm}^{-1}$ ester $\mathrm{C}=\mathrm{O}$ ), due to chemical depolymerization (residue 1, Figure 1). The FT-IR fingerprint region was consistent with previously published polysaccharide spectra and confirmed the predominant polysaccharide nature of residue $1\left(1000-1250 \mathrm{~cm}^{-1} \mathrm{CO}\right.$ stretching of polysaccharides). Lignin-like aromatic structures (1607, $1513 \mathrm{~cm}^{-1}$ aromatic $\left.\mathrm{C}=\mathrm{C}\right)$, some aliphatic chains $\left(2930 \mathrm{~cm}^{-1}\right.$ $\mathrm{CH})$, and aliphatic olefinic groups $\left(1630 \mathrm{~cm}^{-1} \mathrm{C}=\mathrm{C}\right)$ were also found to be present in smaller proportions (7).

With regard to residue 2 (Figure 4B), the polysaccharide NMR profile is significantly less intense compared to the clearer signals at around 20-40 ppm, assignable to methylene carbons of suberin $(6,7,9,10)$ and the carbonyl resonance at 170-180 $\mathrm{ppm}$. In addition, a small signal is also observed at $130 \mathrm{ppm}$, which could be due to unsaturated carbons in the suberin domain, which is compatible with the predominance of long-chain unsaturated fatty acids in the monomeric composition of the suberin samples studied. This cutinase hydrolysis residue (Figure 5B) showed a FT-IR profile different from that of residue 1, the main difference being the presence of the strong peaks at 1138 and $1112 \mathrm{~cm}^{-1}$ found not to derive from cellulose, but most probably from lignin type structures $(\mathrm{CH}, \mathrm{CO}$ deformation), in agreement with the relative increase in lignin type structures as viewed by NMR. Furthermore, the FT-IR spectra of this cutinase hydrolysis residue also confirmed the presence of aliphatic $\mathrm{CH}$ moieties of suberin-derived structures, in accordance with the other results. The presence of carbonyl groups based on the NMR results could only be confirmed in the FT-IR spectra by the presence of a shoulder at $1740-1720 \mathrm{~cm}^{-1}$.

Sugar Monomer and Residue Analysis after Cellulase Treatment. Solid residues from cutinase hydrolysis (residue 2, Figure 1) and chemical depolymerization (residue 1, Figure 1) were subjected to cellulase treatment, because the FT-IR and solid state ${ }^{13} \mathrm{C}$ NMR analyses suggested that polysaccharides were the predominant components of the residues. Given that the potato peel was previously treated with cellulase, the presence of polysaccharides could be due either to their incomplete removal during the 
Table 3. $\mathrm{CHCl}_{3}$-Soluble Long-Chain Suberin Monomers from Potato Variety Nikola Released by Different Depolymerization Techniques (Percent Values Are Average Percent of Total Peak Area from GC-MS and GC-FID Chromatograms) ${ }^{a}$

\begin{tabular}{|c|c|c|c|c|c|c|c|c|c|c|}
\hline \multirow[b]{3}{*}{ compound } & \multicolumn{6}{|c|}{ chemical depolymerization } & \multicolumn{4}{|c|}{ cutinase hydrolysis } \\
\hline & \multicolumn{2}{|c|}{ monomer 1} & \multicolumn{2}{|c|}{ monomer 2} & \multicolumn{2}{|c|}{ monomer 3} & \multicolumn{2}{|c|}{ monomer-oligomer mix 1} & \multicolumn{2}{|c|}{ monomer 4} \\
\hline & $\%$ & SD & $\%$ & SD & $\%$ & SD & $\%$ & SD & $\%$ & SD \\
\hline$\alpha, \omega$-dioic acids & 39.98 & 0.39 & 51.03 & 4.00 & 38.20 & 2.90 & 63.29 & 3.41 & 12.76 & 0.80 \\
\hline hexadecane-1,16-dioic acid & 0.36 & 0.04 & 0.56 & 0.19 & 0.40 & 0.03 & 0.70 & 0.13 & 0.11 & 0.03 \\
\hline octadec-9-ene-1,18-dioic acid (3) & 36.62 & 0.32 & 47.41 & 4.02 & 33.73 & 1.98 & 59.67 & 3.62 & 12.07 & 0.68 \\
\hline octadecane-1,18-dioic acid & 0.51 & 0.02 & 0.55 & 0.08 & 0.43 & 0.08 & 0.72 & 0.07 & 0.19 & 0.02 \\
\hline 9,10-dihydroxyoctadecane-1,18-dioic acid & 0.13 & 0.04 & - & & 0.13 & 0.07 & 0.54 & 0.07 & 0.25 & 0.04 \\
\hline 9,10-epoxyoctadecane-1,18-dioic acid $(9)^{b}$ & 1.18 & 0.03 & - & & 1.30 & 0.51 & - & & 0.19 & \\
\hline eicosane-1,20-dioic acid & ns & & 0.45 & 0.10 & ns & & - & & - & \\
\hline docosane-1,22-dioic acid & 0.49 & 0.03 & 0.32 & 0.05 & 0.36 & 0.04 & 0.36 & 0.08 & 0.20 & \\
\hline tetracosane-1,24-dioic acid & 0.49 & 0.02 & 0.44 & 0.29 & 0.37 & 0.11 & 0.40 & 0.10 & - & \\
\hline hexacosane-1,26-dioic acid & 0.20 & 0.02 & - & & 0.80 & 0.76 & 0.14 & 0.05 & - & \\
\hline octacosane-1,28-dioic acid & $\operatorname{tr}$ & & - & & 0.19 & 0.08 & 0.12 & & - & \\
\hline$\omega$-hydroxy acids & 32.71 & 0.36 & 24.25 & 3.38 & 32.76 & 1.68 & 7.96 & 1.20 & 38.82 & 2.46 \\
\hline 16-hydroxyhexadecanoic acid & 0.25 & 0.02 & 0.32 & 0.09 & 0.30 & 0.06 & 0.11 & 0.06 & 0.56 & 0.03 \\
\hline 18-hydroxyoctadecadienoic acid & 0.17 & 0.03 & - & & 0.11 & 0.03 & - & & 0.20 & 0.05 \\
\hline 18-hydroxyoctadec-9-enoic acid (4) & 27.61 & 0.32 & 21.63 & 3.43 & 26.84 & 1.84 & 6.57 & 1.31 & 33.30 & 2.75 \\
\hline 18-hydroxyoctadecanoic acid & $\operatorname{tr}$ & & - & & tr & & - & & 0.11 & 0.02 \\
\hline 9,10-epoxy-18-hydroxyoctadecanoic acid ${ }^{b}$ & 0.77 & 0.03 & - & & 0.89 & 0.07 & - & & 0.11 & \\
\hline 9,10,18-trihydroxyoctadecanoic acid & 0.12 & 0.01 & 0.10 & 0.02 & 0.15 & 0.03 & 0.20 & 0.02 & 0.28 & 0.13 \\
\hline 20-hydroxyeicosanoic acid & $\operatorname{tr}$ & & - & & $\operatorname{tr}$ & & - & & 0.07 & \\
\hline 22-hydroxydocosanoic acid (11) & 1.31 & 0.05 & 0.70 & 0.20 & 1.28 & 0.05 & 0.53 & 0.17 & 1.57 & 0.25 \\
\hline 24-hydroxytetracosanoic acid (14) & 1.51 & 0.02 & - & & 1.51 & 0.09 & 0.45 & 0.03 & 2.00 & 0.48 \\
\hline 26-hydroxyhexacosanoic acid & 0.66 & 0.02 & 0.71 & 0.08 & 0.95 & 0.01 & 0.20 & 0.04 & 0.92 & 0.22 \\
\hline 28-hydroxyoctacosanoic acid & 0.25 & 0.03 & - & & 0.47 & 0.09 & - & & 0.38 & 0.07 \\
\hline aromatics & 2.27 & 0.27 & 2.43 & 0.52 & 2.58 & 0.21 & 2.05 & 0.50 & 1.49 & 0.65 \\
\hline 4-hydroxy-3-methoxybenzaldehyde & $\operatorname{tr}$ & & 0.18 & 0.02 & 0.26 & 0.03 & ns & & ns & \\
\hline 4-hydroxy-3-methoxybenzoic acid & 0.10 & 0.05 & 0.20 & 0.08 & 0.14 & 0.01 & 0.08 & 0.04 & - & \\
\hline coumaric acid & $\operatorname{tr}$ & & 0.13 & 0.03 & $\operatorname{tr}$ & & - & & $\operatorname{tr}$ & \\
\hline ferulic acid (1) & 2.03 & 0.24 & 1.99 & 0.39 & 2.14 & 0.15 & 1.98 & 0.47 & 1.47 & 0.64 \\
\hline fatty alkanols and diols $(2,5,13)$ & 4.51 & 0.31 & 3.30 & 0.60 & 8.10 & 1.07 & 0.69 & 0.14 & 10.26 & 0.17 \\
\hline fatty acids $(10,12,15)$ & 6.29 & 0.23 & 3.87 & 0.31 & 9.42 & 1.46 & 9.41 & 0.99 & 7.95 & 0.49 \\
\hline hydrocarbons & - & & - & & - & & - & & 6.73 & 2.34 \\
\hline unidentified $(6,7,8)$ & 14.28 & 0.20 & 15.11 & 1.26 & 8.97 & 1.85 & 16.60 & 3.01 & 22.00 & 1.35 \\
\hline total & 100 & & 100 & & 100 & & 100 & & 100 & \\
\hline
\end{tabular}

${ }^{a}$ SD, standard deviation; - , not detected; ns, not separated from unidentified peak; $\mathrm{tr},<0.1 \%$. Number in parentheses after the compound name refers to peak identifications in Figure $3 .{ }^{b}$ Identified as corresponding methoxyhydrin compounds. Positions of double bond not confirmed by chemical methods.

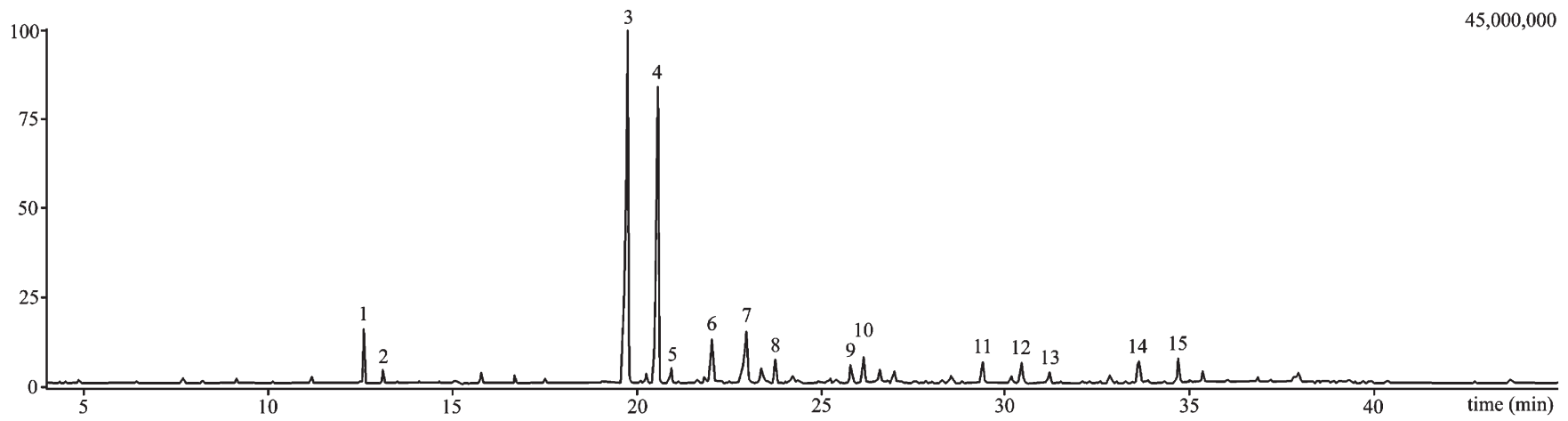

Figure 3. Total ion chromatogram from GC-MS of monomer 1 (Figure 1). For peak identification see retention times in Table 2 and numbers for major peaks in Table 3.

isolation procedure or to the shielding effect of suberin polyaliphatic layers, which hindered cellulase hydrolysis. Residue 1 was also treated as a control, which confirmed that there were no side reactions in the process without the cellulase (measured with FT-IR and solid state ${ }^{13} \mathrm{C}$ NMR). GC sugar analysis of the reaction products confirmed glucose as the main product $(>90 \%)$, followed by minor amounts of xylose and arabinose (together accounting for $5-10 \%$ of the area of glucose peaks). Compounds were identified with the aid of the mass spectra of reference compounds and retention behavior. Noncellulosic residues from this reaction represented about 50 and $70 \%$ of the original mass of the cutinase hydrolysis residue and the chemical depolymerization residue, respectively. These residues were analyzed with solid state ${ }^{13} \mathrm{C} C \mathrm{P}$ MAS NMR techniques and 

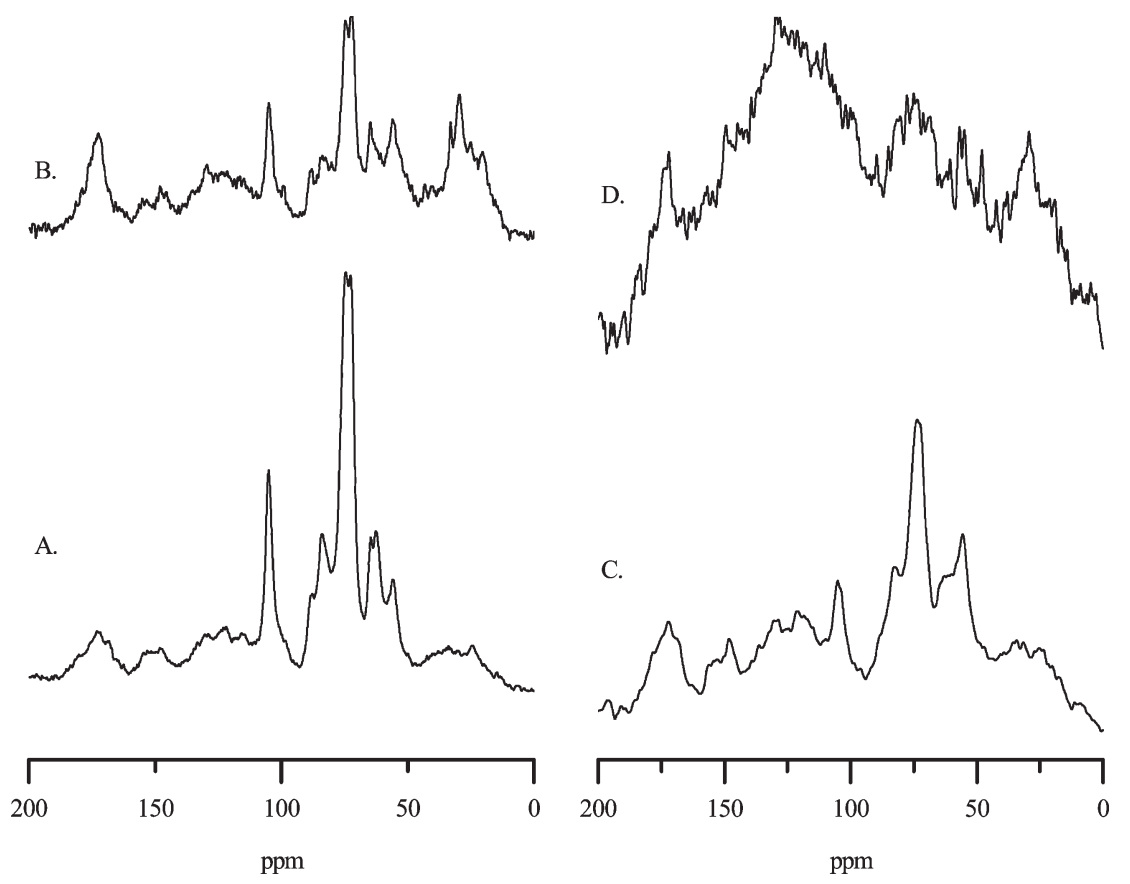

Figure 4. ${ }^{13} \mathrm{C}$ CP MAS NMR spectra of (A) chemical depolymerization residue (residue 1, Figure 1), ns = 6300; (B) cutinase hydrolysis residue (residue 2 , Figure 1), ns = 28650; (C) cellulase-treated chemical depolymerization residue (residue 4, Figure 1), ns = 1980; and (D) cellulase-treated cutinase hydrolysis residue (residue 5, Figure 1), ns $=16540$.

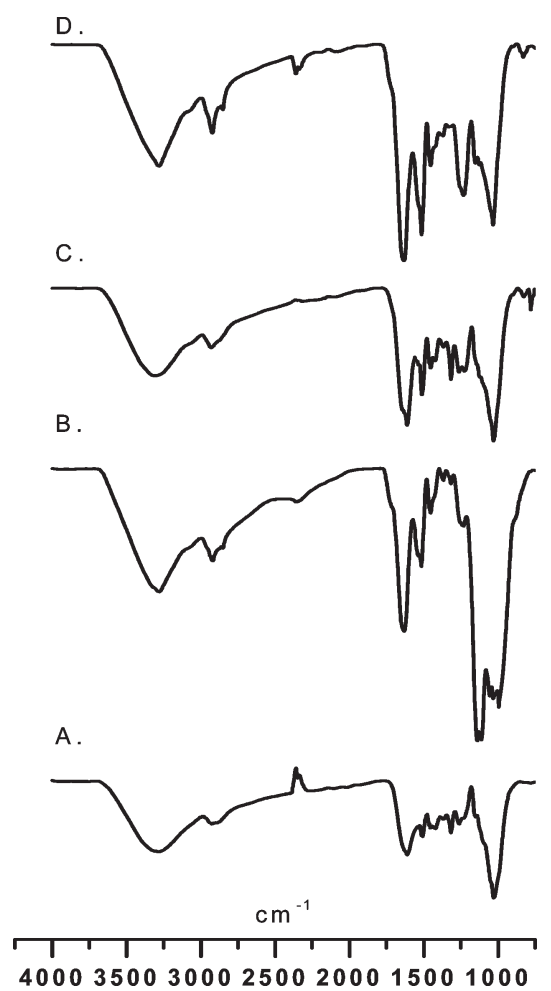

Figure 5. FT-IR spectra of (A) chemical depolymerization residue (residue 1, Figure 1): (B) cutinase hydrolysis residue (residue 2, Figure 1); (C) cellulase-treated chemical depolymerization residue (residue 4, Figure 1); (D) cellulase-treated cutinase hydrolysis residue (residue 5, Figure 1).

by FT-IR, and the spectra obtained were compared with those of the residues before cellulase treatment.

The ${ }^{13} \mathrm{C}$ NMR spectra of the cellulase-treated residues (Figure 4C,D) clearly had less intense resonances from polysaccharides, as expected. Interestingly, the cellulase-treated residue from the cutinase treatment (residue 5, Figure 4D) shows that complete cellulose removal was achieved, the spectrum showing only broad aromatic resonances (100-155 ppm), with residual resonances in other spectral regions. This broad spectrum is consistent with the total collapse of cellular structure upon the additional cellulase treatment, leading to a more amorphous and disorganized structure. The corresponding FT-IR spectrum (Figure 5D) also changes significantly, with the 1138 and $1112 \mathrm{~cm}^{-1}$ peaks being removed, leaving peaks at 1630, 1513, and $1230 \mathrm{~cm}^{-1}$ predominating, which suggests that lignin-like structure was significantly affected. On the other hand, the FT-IR spectrum of residue 4 (Figure 5C) still confirms the presence of all components, although in different proportions.

Microscopy of the Residues. Raw suberin fractions were treated both with cutinase CcCUT1 and with Optimyze 525, examined with confocal microscopy (CLMS, Figure 6), and compared with the raw suberin fraction without any enzymatic treatment. In this study, suberized cell walls were localized using lipophilic Nile Blue stain. The active ingredient in Nile Blue is its fluorescent oxidation product called Nile Red, which is chemically a neutral benzophenoxazone. Nile Red is a general lipid stain, but it shows the most intense fluorescence for nonpolar solvents such as neutral lipids $(28-30)$. Suberin detection using Nile Red is probably based on its attachment to the aliphatic part of the suberin macromolecules.

According to the confocal microscopic analysis, both enzymes CcCUT1 and Optimyze effectively hydrolyzed the suberized cell walls in the raw suberin samples (Figure 6). In all samples, suberin appeared as yellow lamellar structures and the cellular network of potato periderm was apparent. In the reference samples, suberin was seen as a continuous lamellar component surrounding the cork cells (Figure 6A,D). After enzyme treatment with the cutinase CcCUT1 (residue 6, Figure 1), suberin layers were only weakly visible when imaged from the top of the sample. In the cross section, suberin lamellae still showed the cellular network in the middle of the sample, but the outer layers of the sample had reduced fluorescence for suberin when compared to the reference 


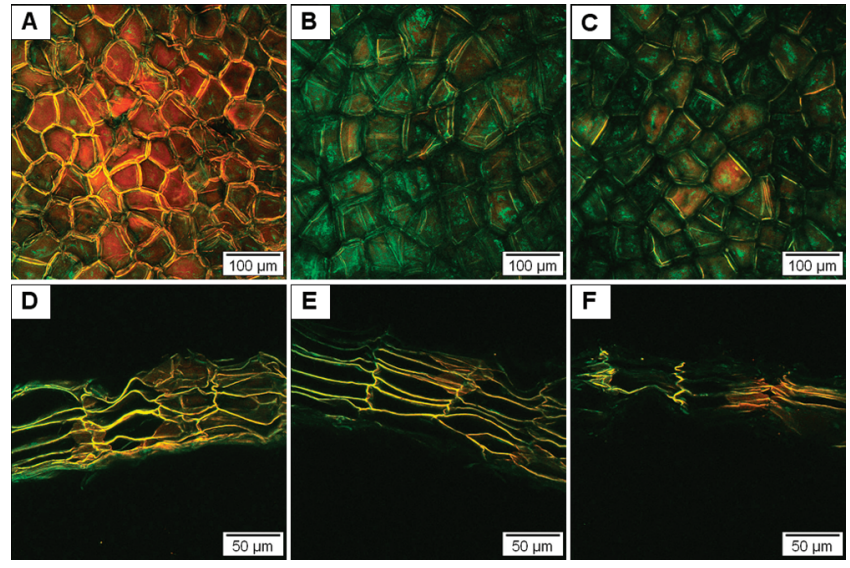

Figure 6. Microstructure of isolated potato suberin ( $\mathbf{A}-\mathbf{C}$ from top, $\mathbf{D}-\mathbf{F}$ cross section) after cutinase treatments with $\operatorname{CCCUT1}(\mathbf{B}, \mathbf{E})$ and Optimyze (C, F). Reference sample (A, D) was incubated without enzyme $\left(50^{\circ} \mathrm{C}\right.$, $\mathrm{pH} 8,24 \mathrm{~h}, 500$ nkat L $^{-1}, 6.3 \mathrm{mg} \mathrm{L}^{-1}$ hydrophobin II, MTBE extraction).

(Figure 6B,E). Fairly similar effects were obtained in the sample treated with the Optimyze 525 enzyme preparation (residue 7 , Figure 1). However, suberin seemed to be more efficiently hydrolyzed with Optimyze 525, as some cell walls did not show any fluorescence at all but some were still brightly fluorescent (Figure 6C,F). The composition of the red-stained layer observed on the surface of the isolated suberized potato membrane, which was also affected by the enzymes, is not known (Figure 6A). It may contain esterified waxes or other fatty substances as it was clearly affected by the enzyme treatments.

In CLSM micrographs, suberin was expected to be localized in the structures that were stained yellow, because they were the sites that showed fluorescence through all of the emission spectra expected for the lipid stain used. Structures seen in the micrographs as green or red might contain fatty substances, as it is known that the emission maximum of Nile Red stain depends on the lipid composition (30). However, their emission spectra differed from those of the yellow structures recognized as suberin lamellae, even though they were affected by the enzyme treatments. On the basis of the microscopic data, it seems that chemical depolymerization results in more effective depolymerization of suberin than the enzymatic procedures with CcCutl and Optimyze. These data support the information obtained from chromatographic and spectroscopic analysis.

Residues from chemical depolymerization (residue 1, Figure 1) and those from cutinase hydrolysis that were further depolymerized by methanolysis (residue 3, Figure 1) were analyzed by light microscopy, because their fine particle size was not suitable for confocal microscopy. The microscopic examination revealed that residues 1 and 3 (Figure 7) did not contain any structures showing bright orange fluorescence typical of the suberin-containing particles stained with Oil Red O (Figure 7). However, the lamellar, slightly brownish structures observed in the samples may be the remains of the suberized cell walls left after the depolymerization treatments.

Monitoring of Cutinase Hydrolysis by the Release of Monomeric and Oligomeric Fatty Acids. The enzymatic hydrolysis by CcCUT1 and Optimyze 525 of the samples subjected to microscopic analysis (residue 6 and 7, Figure 1) was also analyzed by determining the fatty acids released (monomer-oligomer mix 2, Figure 1). The Free Fatty Acids Kit (Roche) used is limited to fatty acids with carbon chain lengths between $\mathrm{C}_{8}$ and $\mathrm{C}_{18}$ and does not therefore necessarily represent the total amount of suberin monomers released. The method can nevertheless be used
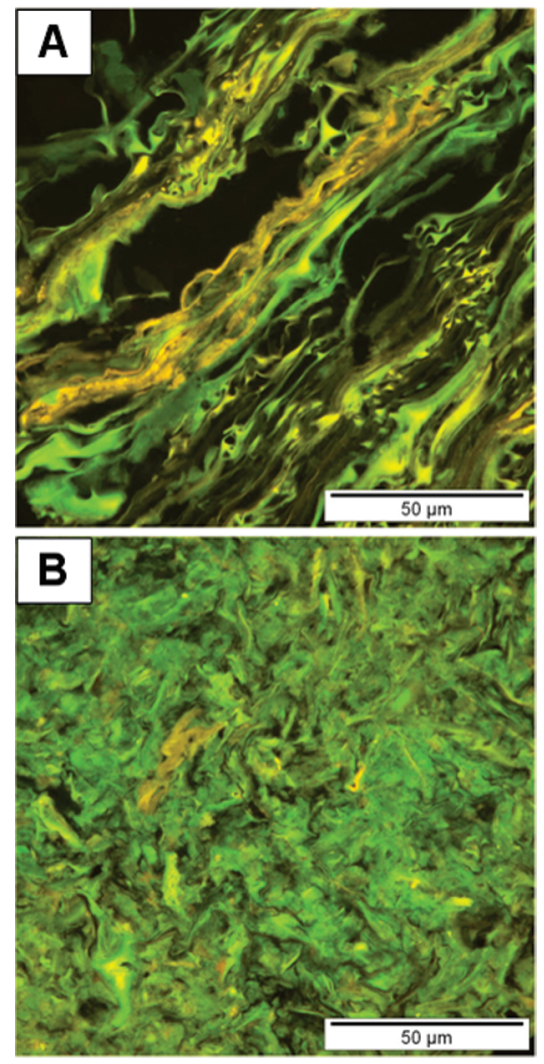

Figure 7. Microstructure of modified potato suberin fractions stained with Oil Red $\mathrm{O}$ and imaged using epifluorescence microscopy: (A) potato suberin residue after chemical depolymerization (residue 1, Figure 1); (B) residue after cutinase hydrolysis and chemical depolymerization (residue 3, Figure 1).

for estimating the amounts of oligomers and monomers released. As shown in Table 4, monomeric fatty acids were released from the raw suberin with equal efficiency by Optimyze 525 and CcCUT1. However, as calculated from the values presented in Table 4, more suberin oligomers were released by Optimyze 525 treatment (approximately $31 \% \mathrm{~mol} / \mathrm{mol}$ ) than by treatment with CcCUT1 (approximately $11 \% \mathrm{~mol} / \mathrm{mol}$ ). This result corresponds with the results from the microscopic analysis described above.

The hydrolytic action of CcCUT1 has previously been investigated with birch outer bark suberin and apple cutin as the substrates (17). Roughly 2 times more fatty acids (as moles) was released from suberin than from cutin. The amount of fatty acids released per mass of substrate $\left(0.22 \mu \mathrm{mol} \mathrm{mg}^{-1}\right.$ of both monomeric and oligomeric fatty acids) in the presence of CcCUT1 in the present study was of the same order of magnitude as the amount of released fatty acids reported previously $(0.29 \mu \mathrm{mol}$ $\mathrm{mg}^{-1}$ of both monomeric and oligomeric), although less enzyme (one-fifth) and a shorter incubation time (half) were used in the previous study. It is thus possible that suberin is in general more recalcitrant toward hydrolysis by CcCUT1 than the true substrate, cutin.

The combined chemical and enzymatic procedures made it possible to compare the two unit operations with each other, even though none of the hydrolytic steps were quantitative. GC analysis of the monomers of the suberin hydrolysates, sugar analysis of the evident cellulose polymer, and FT-IR and solid state ${ }^{13}$ CNMR analyses supplemented with the microscopic investigations gave new information of the inexactly defined raw suberin fraction of potato peels. Cutinase treatment seemed to leave some of the ester bonds unattacked, and methanolysis 
Table 4. Monomeric and Oligomeric Fatty Acids Released from Isolated Suberin during Enzymatic Hydrolysis ${ }^{a}$

\begin{tabular}{lccccc}
\hline & \multicolumn{2}{c}{ monomeric fatty acids $^{b}$} & & monomeric and oligomeric fatty acids ${ }^{b, c}$ \\
\cline { 2 - 3 } \cline { 5 - 6 } enzyme & $\mu \mathrm{mol} / \mathrm{mg}$ & $\%(\mu \mathrm{mol} / \mu \mathrm{mol})$ & & $\mu \mathrm{mol} / \mathrm{mg}$ & $\%(\mu \mathrm{mol} / \mu \mathrm{mol})$ \\
\hline reference & 0.00 & 0 & & 0.00 & 0 \\
CcCUT1 & 0.18 & 46 & & 0.22 & 57 \\
Optimyze & 0.16 & 42 & & 0.28 & 73 \\
\hline
\end{tabular}

${ }^{a}$ The values presented refer to those fatty acids that can be detected with the Fatty Acids Kit. Errors were $<10 \%$. ${ }^{b}$ Per mass of isolated suberin. ${ }^{c}$ After alkali hydrolysis of the oligomers.

released significantly more monomeric fragments than the enzymatic treatment. The proportion of dioic acids was clearly dominating in the enzymatic hydrolysate.

We have not tested specificities and activities of different cutinases or esterases on the raw suberin fraction of potato peels. The analytical scheme including chemical hydrolysis and cutinase and cellulose treatments gives us, however, an indication that the formation of the potato peel during storage might occur via formation of alternating layers. This could, in turn, be verified by "peeling" the raw suberin fraction at different time periods during one year with repeated chemical, esterase, and cellulase treatment steps. The few microscopic investigations of ours supported the relevance of this strategy.

\section{ABBREVIATIONS USED}

$\mathrm{NaOMe}$, sodium methoxide; TMS, trimethylsilyl; GC-MS, gas chromatography-mass spectrometry; FID, flame ionization detector; NMR, nuclear magnetic resonance; FT-IR, Fourier transform infrared; MTBE, methyl tert-butyl ether; HMDS, hexamethyldisilizane; TMCS, trimethylchlorosilane; CPMAS, cross-polarization magic angle spinning.

\section{ACKNOWLEDGMENT}

Saara Mikander, Ritva Heinonen, and Liisa Änäkäinen are thanked for technical assistance and Perunajaloste Koivuranta is thanked for supplying the potatoes for the study.

\section{LITERATURE CITED}

(1) Kolattukudy, P. E. Suberin from plants. In Biopolymers; Steinbüchel, A., Doi, Y., Eds.; Wiley-VCH: Weinheim, Germany, 2001; pp 41-73.

(2) Bernards, M. A. Demystifying suberin. Can. J. Bot. 2002, 80, 227-240.

(3) Gandini, A.; Pascoal Neto, C.; Silvestre, A. J. D. Suberin: a promising renewable resource for novel macromolecular materials. Prog. Polym. Sci. 2006, 31, 878-892.

(4) Lopes, M. H.; Gil, A. M.; Silvestre, A. J. D.; Pascoal Neto, C. Composition of suberin extracted upon gradual alkaline methanolysis of Quercus suber L. Cork. J. Agric. Food Chem. 2000, 48, 383-391.

(5) Graça, J.; Pereira, H. Suberin structure on potato periderm: glycerol, long-chain monomers, and glyceryl and feruloyl dimers. J. Agric. Food Chem. 2000, 48, 5476-5483.

(6) Lopes, M. H.; Pascoal Neto, C.; Barros, A. S.; Rutledge, D.; Delgadillo, I; Gil, A. M. Quantitation of aliphatic suberin in Quercus suber L. cork by FT-IR spectroscopy and solid-state ${ }^{13} \mathrm{C}$ NMR Spectroscopy. Biopolymers 2000, 57, 344-351.

(7) Rocha, S. M.; Goodfellow, B. J.; Delgadillo, I.; Pascoal Neto, C.; Gil, A. M. Enzymatic isolation and structural characterization of polymeric suberin of cork from Quercus suber L. Int. J. Biol. Macromol. 2001, 28, 107-119.

(8) Pacchiano, R. A., Jr.; Sohn, W.; Chlanda, V. L.; Garbow, J. R.; Stark, R. E. Isolation and spectral characterizaion of plant-cuticle polyesters. J. Agric. Food Chem. 1993, 41, 78-83.
(9) Garbow, J. R.; Ferrantello, L. M.; Stark, R. E. ${ }^{13}$ C nuclear magnetic resonance study of suberised potato cell wall. Plant Physiol. 1989, 90, 783-787.

(10) Gil, A. M.; Lopes, M.; Rocha, J.; Pascoal Neto, C. A ${ }^{13}$ C solid state nuclear magnetic resonance spectroscopic study of cork cell wall structure: the effect of suberin removal. Int. J. Biol. Macromol. 1997, 20 (4), 293-305.

(11) Lapierre, C.; Pollet, B.; Négrel, J. The phenolic domain of potato suberin: structural comparison with lignins. Phytochemistry 1996, 42 (4), 949-953.

(12) Bernards, M. A.; Lewis, N. G. The macromolecular aromatic domain in suberized tissue: a changing paradigm. Phytochemistry 1998, 47, 915-933.

(13) Bernards, M. A.; Razem, F. A. The poly(phenolic) domain of potato suberin: a non-lignin cell wall bio-polymer. Phytochemistry 2001, 57, 1115-1122.

(14) Negrel, J.; Pollet, B.; Lapierre, C. Ether-linked ferulic acid amides in natural and wound periderms of potato tuber. Phytochemistry 1996, 43, 1195-1199.

(15) Kolattukudy, P. E.; Agrawal, V. P. Structure and composition of aliphatic constituents of potato tuber skin (suberin). Lipids 1974, 9 , 682-691.

(16) Brieskorn, C. H.; Binnemann, P. H. Chemical composition of potato peel suberin. Z. Lebens. Unters. Forsch. 1974, 154, 213-222.

(17) Kontkanen, H.; Westerholm-Parvinen, A.; Saloheimo, M.; Bailey, M.; Rättö, M.; Mattila, I.; Mohsina, M.; Nakari-Setälä, T.; Buchert, J. A novel polyesterase from Coprinus cinereus hydrolysing cutin and suberin. Appl. Environ. Microbiol. 2009, 75, 2148-2157.

(18) Carvalho, C. M. L.; Aires Barros, M. R.; Cabral, J. M. S. Cutinase: from molecular level to bioprocess development. Biotechnol. Bioeng. $1999,66,17-34$.

(19) Kallio, H.; Nieminen, R; Tuomasjukka, S.; Hakala, M. Cutin composition of five Finnish berries. J. Agric. Food Chem. 2006, 54, 457-462.

(20) Nakari-Setälä, T.; Aro, N.; Ilmén, M.; Muñoz, G.; Kalkkinen, N.; Penttilä, M. Differential expression of the vegetative and sporebound hydrophobins of Trichoderma reesei: cloning and characterization of the $h f b 2$ gene. Biotechnol. Bioeng. 1997, 248, 415-423.

(21) Holloway, P. J.; Deas, A. H. B. Epoxyoctadecanoic acids in plant cutins and suberins. Phytochemistry 1973, 12, 1721-1735.

(22) Eglinton, G.; Hunneman, D. H.; McCormick, A. Gas chromatographic-mass spectrometric studies of long chain hydroxyacids III. Org. Mass Spectrom. 1968, 1, 593-611.

(23) Eglington, G.; Hunneman, D. H. Gas chromatographic-mass spectrometric studies of long chain hydroxyacids I. Phytochemistry 1968, 7, 313-322.

(24) Rontani, P.-F.; Aubert, C. Trimethylsilyl transfer during electron ionization spectral fragmentation of some $\omega$-hydroxycarboxylic and $\omega$-dicarboxylic acid trimethylsilyl derivatives and the effect of chain length. Rapid Commun. Mass Spectrom. 2004, 18, 1889 1895 .

(25) Tiitinen, K. M.; Yang, B.; Haraldsson, G. G.; Jonsdottir, S.; Kallio, H. P. Fast analysis of sugars, fruit acids, and vitamin $\mathrm{C}$ in sea buckthorn (Hippophae rhamnoides L.) varieties. J. Agric. Food Chem. 2006, 54, 2508-2513.

(26) Olkku, J.; Kotaviita, E.; Salmenkallio-Marttila, M.; Sweins, H.; Home, S. Connection between structure and quality of barley husk. J. Am. Soc. Brew. Chem. 2005, 63, 17-22.

(27) Bento, M. F. S.; Pereira, H.; Cunha, M. Á.; Moutinho, A. M. C.; van den Berg, K. J.; Boon, J. J.; van den Brink, O.; Heeren, R. M. A. Fragmentation of suberin and composition of aliphatic monomers released by methanolysis of cork from Quercus suber L., analysed by GC-MS, SEC, and MALDI-MS. Holzforschung 2001, 55, 487-493.

(28) Greenspan, P.; Mayer, E. P.; Fowler, S. D. Nile red: a selective fluorescent stain for intracellular lipid droplets. J. Cell. Biol. 1985, 100, 965-973.

(29) Fulcher, R. G.; Irving D. W.; de Francisco, A. Fluorescence microscopy: applications in food analysis. In Fluorescence Analysis in Foods; Munck, L., Ed.; Wiley: New York, 1989; 298 pp. 
(30) Barnes, P. J.; Fulcher, R. G. Fluorometric measurement of fats. In Fluorescence Analysis in Foods; Munck, L. Ed.; Wiley: New York, 1989; 298 pp.

Received March 16, 2009. Revised manuscript received August 3, 2009. Accepted August 3, 2009. This work was carried out within the project "Discovery and exploitation of novel lipid modifying enzymes in industrial processes (LIPFUN)" funded by Tekes and companies involved in the project. This study was also supported by the ABS graduate school (Applied Bioscience Bioengineering, Food \& Nutrition, Environment) and COST Action 928, Control and exploitation of enzymes for added-value food products. 